\title{
Carotid body chemosensitivity: early biomarker of dysmetabolism in humans
}

\author{
João P Cunha-Guimaraes ${ }^{1, *}$, Maria P Guarino $0^{1,2, *}$, Ana T Timóteo ${ }^{3}$, Iolanda Caires', Joana F Sacramento \\ Maria J Ribeiro1, Mafalda Selas ${ }^{3}$, João C P Santiago1, Miguel Mota-Carmo ${ }^{1,3, \uparrow}$ and Silvia V Conde ${ }^{1, \dagger}$
}

${ }^{1}$ CEDOC, NOVA Medical School, Faculdade de Ciências Médicas, Universidade NOVA de Lisboa, Lisbon, Portugal, ${ }^{2}$ ciTechCare, Escola Superior de Saúde de Leiria, Instituto Politécnico de Leiria, Leiria, Portugal, and ${ }^{3}$ Serviço de Cardiologia, Hospital Santa Marta, Centro Hospital Lisboa Central, EPE, Lisbon, Portugal

*(J P Cunha-Guimaraes and M P Guarino contributed equally to this work)

${ }^{\dagger}$ (M Mota-Carmo and S V Conde are joint senior authors)

Correspondence should be addressed to S V Conde

Email

silvia.conde@nms.unl.pt

\begin{abstract}
Objective: The carotid bodies (CBs) are peripheral chemoreceptor organs classically described as being $\mathrm{O}_{2}$ sensors, which are increasingly emerging as core players in metabolic control. Herein we evaluated CB activity in prediabetes patients and determined its correlation with dysmetabolism clinical features.

Design and methods: Prediabetes patients were recruited at the Cardiology Service, Hospital Santa Marta, Centro Hospitalar Lisboa Central, EPE (CHLC-EPE). The study was approved by CHLC-EPE and NOVA Medical School Ethics Committee. Thirty-three prediabetic and 14 age-matched, non-prediabetic, volunteers had their peripheral chemosensitivity evaluated by the Dejours test. Serum biomarkers of metabolic disease, insulin sensitivity (HOMA-IR), blood pressure, carotid intima-media thickness (cIMT) and glucose tolerance were assessed.

Results: CB chemosensitivity was significantly increased in prediabetic group $(P<0.01)$. Fasting blood, glucose intolerance, fasting insulin and HOMA-IR were significantly higher in prediabetes patients. Insulin resistance correlated both with peripheral chemosensitivity, assessed by the Dejours test $(P<0.05)$ and with abdominal circumference $(P<0.01)$. HbA1c correlated with HOMA-IR $(P<0.05)$ and left $\mathrm{CIMT}(P<0.05)$ in prediabetes patients.

Conclusions: We conclude that $\mathrm{CB}$ is overactive in prediabetes subjects and that peripheral chemosensitivity correlates with fasting insulin and insulin resistance representing a novel non-invasive functional biomarker to forecast early metabolic disease.
\end{abstract}

\section{Introduction}

The carotid bodies (CBs) are peripheral chemoreceptors that classically sense changes in arterial blood $\mathrm{O}_{2}, \mathrm{CO}_{2}$ and $\mathrm{pH}$ levels (1). The classical stimulus for the carotid body is hypoxemia, which leads to an increase in CSN activity. Besides its role in the cardiorespiratory control, the $\mathrm{CB}$ has been proposed as a metabolic sensor implicated in the control of energy homeostasis $(2,3)$. There has been huge debate in the literature on the hypothesis that CBs sense glucose and that hyperglycemia may be the trigger for $\mathrm{CB}$ overactivation observed in metabolic
European Journal of Endocrinology

(2020) 182, 549-557 
glucose intolerance $(5,6)$ core features of very prevalent diseases like the metabolic syndrome and type 2 diabetes via activation of the sympathetic nervous system $(7,8$, $9,10)$. We showed that animal models of diet-induced prediabetes develop an increased $\mathrm{CB}$ chemosensitivity $(5,7,9)$ that results in an increase in SNS activity and in a reduction in insulin sensitivity $(4,7,8,9)$. All these characteristic features of metabolic diseases were prevented by CSN resection disclosing CB's primordial role in the control of peripheral insulin sensitivity $(4,5,6,7,8,9$, 11). In agreement with this increased activation of the $\mathrm{CB}$ in dysmetabolic states, the CBs of prediabetic and type 2 diabetic animals are hyperplasic and exhibit a higher percentage of neurosecretory type 1 cells, confirmed by the higher expression of tyrosine hydroxylase $(4,10)$, a molecular marker for this type of cells. Confirming this preclinical data, the CBs of type 2 diabetic patients that are $20-25 \%$ larger than control volunteers (12).

Additionally, the abolishment of $\mathrm{CB}$ activity in animals, via chronic resection of $\mathrm{CB}$ sensitive nerve, the carotid sinus nerve $(\mathrm{CSN})(4,9,11)$ or, alternatively, through its bioelectronic modulation (11) prevented and reversed dysmetabolism in animal models of prediabetes and type 2 diabetes, respectively, by positively impacting glucose uptake and insulin signaling in the liver and in the visceral adipose tissue (8) and by normalizing wholebody sympathetic activity $(8,9)$. More recently, we showed that the diabetic condition can be discriminated on the basis of CSN and sympathetic neural activities due to a high-frequency shift in both spectra (8), being the sympathetic neural activity shift suppressed upon CSN denervation, confirming the role of CSN in driving sympathetic overactivation in type 2 diabetes. Indeed, augmented peripheral chemosensitivity has been shown to contribute not only to type 2 diabetes, but also to several other sympathetic-mediated diseases, as essential hypertension, hypertension associated with sleep apnea and heart failure, both in animal models $(13,14,15,16$, $17,18)$ and in humans $(19,20,21,22,23)$.

In agreement with our pre-clinical data demonstrating the involvement of CB dysfunction in the development of peripheral insulin resistance and glucose intolerance, we have shown that hyperbaric oxygen therapy, a therapeutic approach frequently used to promote wound healing to treat diabetic foot, improves glucose homeostasis in type 2 diabetes patients (24), an effect that is probably mediated by CB inhibition, as hyperoxia dramatically reduces peripheral chemoreceptor activity (25).

Thus, the CBs emerge as an innovative therapeutic target for patients with metabolic diseases associated to overactivation of the sympathetic nervous system (26), but evidence is still lacking as to the relation between increased CB firing rate and the subclinical development of dysmetabolism in humans.

The general aim of the present work was to investigate if $\mathrm{CB}$ chemosensitivity is altered in prediabetes patients. The hypothesis tested was that $\mathrm{CB}$ chemosensitivity is augmented in prediabetes and that $\mathrm{CB}$ activity correlates with classical prediabetes disease features.

\section{Methods}

\section{Ethical approval}

The study was approved by Hospital Santa Marta, Centro Hospitalar Lisboa Central EPE (CHLC-EPE, $n^{\circ}$ 63/2010) and NOVA Medical School Ethics Committee and performed in accordance with the Helsinki Declaration. Written informed consent was obtained from all individuals.

\section{Subjects}

Prediabetes patients were recruited at the Cardiology Service, Hospital Santa Marta, CHLC-EPE. Inclusion criteria for prediabetes were those defined by the American Diabetes Association (27). Exclusion criteria were cardiovascular disorders, except hypertension, renal diseases, obesity hypoventilation syndrome, chronic respiratory failure, and psychiatric diseases. Thirty-three prediabetic patients (age $=64.1 \pm 11.2$ years, $\mathrm{HbA} 1 \mathrm{c}=6.0 \pm 0.5 \%, 36.36 \%$ male: $63.63 \%$ female) exclusively under non-pharmacological treatment for glycemic control and 14 non-prediabetic controls (age $=60.6 \pm 13.4$ years, $\mathrm{HbA1c}=5.5 \pm 0.3 \% ; 50 \%$ male $: 50 \%$ female) were included. The clinical study was conducted in two visits.

\section{Study design and subjects monitoring}

The first visit was at CHLC-EPE where sociodemographic and anthropometric data, comorbidities and ongoing medication profile were documented. Weight, height and abdominal circumference using standardized protocols were assessed. Blood pressure was measured, and hypertension defined by a previous diagnosis of hypertension or the presence of systolic blood pressure $\geq 140 \mathrm{mmHg}$ or diastolic blood pressure $\geq 90 \mathrm{mmHg}$ (mean of two consecutive measurements). Fasting peripheral blood was collected by venopuncture to assess 
Table 1 Demographic, cardiometabolic and ventilatory variables in non-prediabetes individuals $(n=14)$ and prediabetic $(n=33)$ patients. Values are presented as mean \pm S.D.

\begin{tabular}{|c|c|c|c|}
\hline Characteristics & Non-prediabetics & Prediabetics & P value $^{*}$ \\
\hline Age, years & $60.57(3.43)$ & $64.06(11.20)$ & 0.359 \\
\hline $\mathrm{BMI}$ & $27.21(7.36)$ & $30.15(4.56)$ & 0.114 \\
\hline Abd. circumference, $\mathrm{cm}$ & $88.71(15.64)$ & $96.67(12.95)$ & 0.077 \\
\hline Systolic BP, mmHg & $136.60(11.72)$ & $152.90(20.04)$ & 0.007 \\
\hline Diastolic BP, mmHg & $83.57(8.43)$ & $82.48(12.67)$ & 0.769 \\
\hline Gender (Male:Female), \% & $(50 / 50)$ & $(36.36 / 63.63)$ & \\
\hline Insulin, $\mu U \mathrm{UI} / \mathrm{mL}$ & $6.30(3.72)$ & $10.50(7.26)$ & 0.047 \\
\hline HOMA-IR & $1.34(0.88)$ & $2.55(2.21)$ & 0.054 \\
\hline $\mathrm{HbA1c}, \%$ & $5.59(0.31)$ & $6.04(0.52)$ & 0.004 \\
\hline Cholesterol, mg/dL & $198.40(26.64)$ & $186.60(37.21)$ & 0.289 \\
\hline $\mathrm{HDL}-\mathrm{c}, \mathrm{mg} / \mathrm{dL}$ & $57.07(14.10)$ & $50.03(15.23)$ & 0.146 \\
\hline LDL-c, mg/dL & $132.40(23.39)$ & $124.10(29.97)$ & 0.361 \\
\hline $\mathrm{TAG}, \mathrm{mg} / \mathrm{dL}$ & $116.10(52.21)$ & $155.10(96.28)$ & 0.162 \\
\hline Apo A1, mg/dL & $140.10(36.75)$ & $141.70(25.19)$ & 0.863 \\
\hline Apo B, mg/dL & $102.30(18.62)$ & $90.90(22.36)$ & 0.101 \\
\hline $\mathrm{CRP}, \mathrm{mg} / \mathrm{dL}$ & $4.43(9.88)$ & $4.80(4.76)$ & 0.862 \\
\hline Dopamine, $\mathrm{pg} / \mathrm{mL}$ & 93.65 (55.07) & $109.75(136.66)$ & 0.702 \\
\hline Epinephrine, pg/mL & $21.48(13.93)$ & $33.33(25.42)$ & 0.132 \\
\hline Norepinephrine, pg/mL & $276.60(149.90)$ & $326.20(207.80)$ & 0.458 \\
\hline Fasting plasma glucose, $\mathrm{mg} / \mathrm{dL}$ & $67.13(9.31)$ & $90.85(20.89)$ & 0.004 \\
\hline 2-h glycemia, mg/dL & $120.40(12.36)$ & $165.60(41.09)$ & 0.005 \\
\hline RR baseline, bpm & $11.86(2.94)$ & $12.30(3.30)$ & 0.738 \\
\hline VT, L/kg & $6.39(2.18)$ & $8.00(2.17)$ & 0.074 \\
\hline Decrease RR, \% & $4.62(15.43)$ & $-8.48(10.62)$ & 0.010 \\
\hline $\mathrm{NO}, \mu \mathrm{M}$ & $56.45(25.06)$ & $64.49(57.35)$ & 0.687 \\
\hline cIMT right, mm & $0.80(0.14)$ & $0.83(0.18)$ & 0.661 \\
\hline cIMT left, mm & $0.82(0.17)$ & $0.814(0.17)$ & 0.925 \\
\hline
\end{tabular}

fasting plasma insulin, fasting blood glucose, HbA1c, lipid profile as well as other biological parameters (Table 1). Plasma samples were analyzed in the hospital central laboratory and biological parameters quantified using automatic standard routine enzymatic methods. HDL cholesterol was determined after specific precipitation. LDL cholesterol was determined by Friedewald formula. Catecholamines in plasma, assessed as an indirect measurement of sympathetic nervous system activity, were quantified by high performance liquid chromatography with electrochemical detection. Carotid intima-media thickness (cIMT) was assessed by high-resolution B-mode ultrasonography with a Siemens Sonolite ${ }^{\mathrm{TM}}$ system and a 7.5-MHz linear array transducer. In magnified and frozen images, cIMT was measured at the distal common carotid artery ( $1 \mathrm{~cm}$ proximal to the carotid bifurcation) at the far wall. Manual measurements of cIMT were obtained from both, the right and the left side carotids. The lumen/ intima leading edge to media/adventitia leading edge method was used (28). cIMT value used for the present analysis was defined as the maximum value between the right and left common carotids.

The second visit was performed at NOVA Medical School to assess glucose tolerance and peripheral chemosensitivity by the double breath Dejours test (29, 30). Glucose tolerance status was determined by means of an oral glucose tolerance test (OGTT), the standard measure for both glucose intolerance and diabetes diagnosis. Briefly, the OGTT consisted in the oral administration of a glucose drink with orange flavor containing 75 g glucose (Top Star 75, Toplabs, Portugal) and in the measurement of blood glucose before and $2 \mathrm{~h}$ after ingestion. The OGTT was performed in fasting volunteers on the day the Dejours test was performed. Fasting blood glucose 
levels were quantified with a glucometer (Precision Xtra Meter, Abbott Diabetes Care, Portugal) and test strips (Abbott Diabetes Care, Portugal). To perform the Dejours test, ventilation, namely respiratory frequency (RR) and tidal volume (VT) were measured, while subjects breathed room air $\left(21 \% \mathrm{O}_{2}\right.$; normoxia) followed by two breaths of $100 \% \mathrm{O}_{2}$ (hyperoxia) delivered at a $10 \mathrm{~L} / \mathrm{min}$ flow and by normoxia again, via a mouthpiece connected to a threeway valve in a whole-body plethysmography system (MasterScreen Body, Jaeger, Germany). Hyperoxia applied during a few seconds resulted in a decrease in ventilation that reflects $C B$ chemosensitivity $(29,30)$ and can be expressed as a percentage of the pre-oxygen breathing respiratory frequency. \% decrease in RR and VT was calculated as follows: mean of RR or VT values during the period of time from which $100 \% \mathrm{O}_{2}$ is applied to the time where RR or VT values return to baseline values minus the mean of RR or VT during exposure to air (Fig. 1A). The maneuver was repeated three times in each patient to assess reproducibility of the test.
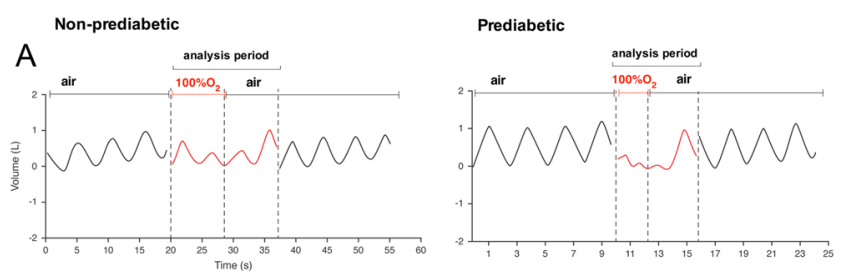

B
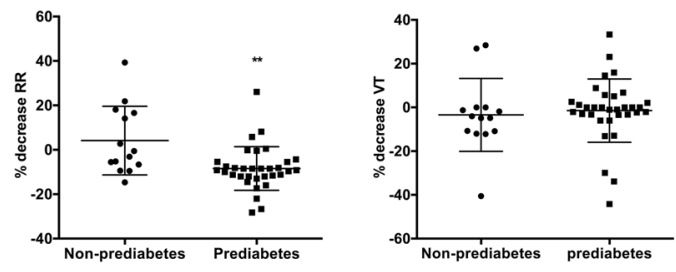

\section{Figure 1}

Carotid body chemosensitivity in non-prediabetes and prediabetes subjects. (A) Show typical spirograms for the effect of $100 \% \mathrm{O}_{2}$ (hyperoxia) on the spontaneous ventilation in non-prediabetes (Left panel A) and in prediabetes (Right panel A) individuals; (B) left panel depicts carotid body chemosensitivity evaluated as the $\%$ of decrease in respiratory rate produced by two breaths of $100 \% \mathrm{O}_{2}$ (Dejours test). Right panel shows the absence of differences between prediabetes and non-prediabetes patients on $\%$ of decrease in tidal volume. Two breaths of hyperoxia were applied to evaluate CB sensitivity. Red line shows the period of time used to calculate mean respiratory rate (RR) and mean tidal volume (VT) to access the effect of hyperoxia on these variables. Values are mean \pm S.D. $* * P<0.01$.

\section{Statistical analysis}

Statistical analysis was performed using the GraphPad Prism Software, version 6 and PASW 18.0 program (SPSS Inc). $P$ values of 0.05 or less were considered to represent significant differences.

Quantitative variables were described as mean and standard deviation. Normality was assessed with Kolmogorov-Smirnov test. Qualitative variables are presented as percentages. ANOVA test or Kruskal-Wallis test was used for between group comparisons of continuous variables (according to distribution characteristics), while chi-square test was used for between group comparisons of categorical variables.

To investigate the variables associated with $\mathrm{CB}$ chemosensitivity in prediabetic patients we evaluated Spearman's correlation coefficient. Multivariable analysis using a stepwise multiple linear regression analysis was performed to study the association between the defined independent variables and $\mathrm{CB}$ chemosensitivity, as dependent variable (Table 3). Also, a stepwise multiple linear regression analysis was performed considering HOMA and HbA1c, as dependent variables (Table 4).

\section{Results}

Demographic, cardiometabolic and ventilatory variables in controls (non-prediabetes patients) and prediabetics are depicted in Table 1 and drug therapy in Table 2. Fasting and 2-h blood glucose following OGTT were $94.3 \pm 16.2$ $\mathrm{mg} / \mathrm{dL}$ and $165.6 \pm 41.1 \mathrm{mg} / \mathrm{dL}$ in prediabetes $(P<0.001)$, and $84.5 \pm 9.9 \mathrm{mg} / \mathrm{dL}$ and $120.4 \pm 12.3 \mathrm{mg} / \mathrm{dL}$ in control patients, respectively. Plasma fasting insulin levels and HOMA-IR were $10.5 \pm 7.3 \mu \mathrm{UI} / \mathrm{mL}(P<0.01)$ and $2.4 \pm 2.2$ $\mu \mathrm{UI} / \mathrm{mL}(P<0.05)$, in prediabetes volunteers, and $6.3 \pm 3.7$ $\mu \mathrm{UI} / \mathrm{mL}$ and $1.3 \pm 0.9 \mu \mathrm{UI} / \mathrm{mL}$ in controls. No significant differences were observed in the lipid profile between nonprediabetes and prediabetes subjects. Total cholesterol, HDL-c, LDL-c and triglycerides levels were, respectively, $186.6 \pm 37.2 \mathrm{mg} / \mathrm{dL}, 50.03 \pm 15.2 \mathrm{mg} / \mathrm{dL}, 124.1 \pm 30.0 \mathrm{mg} /$ $\mathrm{dL}, 155.1 \pm 52.2 \mathrm{mg} / \mathrm{dL}$ in prediabetics and $198.40 \pm 26.6$ $\mathrm{mg} / \mathrm{dL}, \quad 57.1 \pm 14.1 \mathrm{mg} / \mathrm{dL}, \quad 132.4 \pm 23.4 \mathrm{mg} / \mathrm{dL}$ and $116.1 \pm 52.21$ in non-prediabetics. Figure $1 \mathrm{~A}$ depicts representative spirograms of basal ventilation (black line, air) and Dejours test (1st 2 breaths of the red line) in a nonprediabetes and in a prediabetes volunteer. The Dejours test has proven to be reproducible in specific populations (31) and we also tested its reproducibility, by performing three replicate tests in each participant. No significant 
Table 2 Risk factors and drug therapy in non-prediabetes individuals $(n=14)$ and prediabetic $(n=33)$ patients. Variables are presented as $n(\%)$.

\begin{tabular}{l}
\hline \\
\hline Risk factors, $n(\%)$ \\
Smoking \\
Coffee \\
Hypertension \\
Dyslipidemia \\
Medication, $n(\%)$ \\
$\beta$-blocker \\
ARB \\
Statin \\
Calcium-channel blocker \\
Diuretics \\
ACE inhibitor \\
Fibrates \\
Anti-platelet agents \\
\hline
\end{tabular}

\begin{tabular}{c}
\hline Non-prediabetics \\
\hline $3(21.43)$ \\
$7(50.00)$ \\
0 \\
$1(7.14)$ \\
$1(7.14)$ \\
$3(21.43)$ \\
$5(35.71)$ \\
$3(21.43)$ \\
$4(28.57)$ \\
$4(28.53)$ \\
0 \\
0
\end{tabular}

\begin{tabular}{c}
\hline Prediabetics \\
\hline $5(14.71)$ \\
$20(58.82)$ \\
$8(23.53)$ \\
$9(26.47)$ \\
$12(35.29)$ \\
$12(35.29)$ \\
$14(41.18)$ \\
$7(20.59)$ \\
$7(20.59)$ \\
$13(38.24)$ \\
$3(8.82)$ \\
$3(8.82)$ \\
\hline
\end{tabular}

\begin{tabular}{c}
\hline P value \\
\hline \\
0.534 \\
0.646 \\
$\mathbf{0 . 0 4 8}$ \\
0.140 \\
\\
$\mathbf{0 . 0 4 7}$ \\
0.357 \\
0.732 \\
0.949 \\
0.560 \\
0.535 \\
0.260 \\
0.260
\end{tabular}

$\star P<0.05$, one-way ANOVA.

$A R B$, angiotensin receptor blocker; ACE. angiotensin-converting enzyme.

variation among the replicates was observed (data not shown). In our experimental setting, we observed that the prediabetic subject presents both a higher tidal volume (VT, $P=0.074$ ) and a higher respiratory rate (RR, $P=0.738$ ) (Fig. 1A and Table 1) in comparison with the nonprediabetic. As expected, 2 breaths of $100 \% \mathrm{O}_{2}$ decreased ventilation (Fig. 1). A statistically significant increase in $\mathrm{CB}$ chemosensitivity was detected in prediabetic patients since the $\%$ of decrease in RR, produced by 2 breaths of $100 \% \mathrm{O}_{2}$, was higher in this group than in the non-prediabetes group as depicted in the representative spirograms of Fig. 1 (\% decrease RR prediabetes $=-8.48 \pm 10.62$ vs \%decrease RR controls $=4.62 \pm 15.43, P<0.01$, Fig. $1 \mathrm{~A}$ and B). No differences were seen between the prediabetic and nonprediabetic group on the $\%$ of decrease in tidal volume produced by 2 breaths of $100 \% \mathrm{O}_{2}$ (\% decrease VT controls $=-3.43 \pm 16.66 \%$; Fig. 1B right panel).

Right and left cIMT were $0.83 \pm 0.2 \mathrm{~mm}$ and $0.81 \pm 0.2$ $\mathrm{mm}$, respectively, in prediabetes patients and $0.80 \pm 0.1$ $\mathrm{mm}$ and $0.82 \pm 0.2 \mathrm{~mm}$, in the control group. Spearman analysis found significant correlations between $\mathrm{CB}$ chemosensitivity and both, insulin levels $(r=-0.58$, $P<0.01)$, and HOMA-IR $(r=-0.46, P<0.05)$, but no correlation among other variables tested (Supplementary Table 1 , see section on supplementary materials given at the end of this article).

Lastly, using a multivariable analysis, by the stepwise method, we found that in prediabetes subjects, the dependent variable Dejours test only correlated with the independent variable, plasma fasting insulin levels $(P=0.042)$ and, therefore, with HOMA-IR (Table 3). Additionally, the dependent variables HOMA-IR and HbA1c correlated with the independent variables: abdominal circumference $(P=0.006)$ and Dejours test $(P=0.026)$ and with HOMA-IR $(P=0.018)$ and left cIMT $(P=0.043)$, respectively (Table 4$)$.

\section{Discussion}

Herein we tested the proof of concept that augmented CB chemosensitivity is a clinical feature in prediabetes. The main novel finding is that $\mathrm{CB}$ chemosensivity correlates with fasting plasma insulin levels and with HOMA-IR index in prediabetes patients, classical markers of insulin resistance. This study carries a significant innovative potential since it shows that $\mathrm{CB}$ overactivity in humans may represent a non-invasive and accurate functional biomarker of hyperinsulinemia and insulin resistance.

Although being a pilot study, the results are statistically robust and show that prediabetes patients exhibit increased CB chemosensitivity and that disrupted $\mathrm{CB}$ activity patterns are linked to circulating insulin and to insulin resistance. Herein, $\mathrm{CB}$ chemosensitivity was evaluated by 2 breaths of $100 \% \mathrm{O}_{2}$, the double-breath Dejours test $(29,30)$, as with this test is possible to obtain a change in the oxygen drive almost free of secondary factors since they are secondary in time $(30,32)$. Indeed, if $100 \% \mathrm{O}_{2}$ is breathed during prolonged exposures (several minutes) ventilation does not change or even can increase (32). The increased $\mathrm{CB}$ chemosensitivity observed in prediabetes patients was mainly seen in RR but not in tidal volume (Fig. 1B). This increased CB chemosensitivity, clearly manifested in the \% of reduction in RR was also 
Table 3 Multivariable analysis between the dependent variable carotid body chemosensitivity (\% decrease in RR) and the independent variables using the stepwise method.

\begin{tabular}{|c|c|c|}
\hline \multirow{2}{*}{$\begin{array}{l}\text { Independent } \\
\text { variable }\end{array}$} & \multicolumn{2}{|c|}{ CB chemosensitivity (\% decrease RR) } \\
\hline & Unstandardized coefficients B & $P$ value \\
\hline \multicolumn{3}{|c|}{ 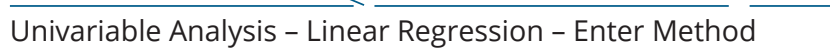 } \\
\hline Age & -0.174 & 0.449 \\
\hline $\mathrm{BMI}$ & 0.004 & 0.994 \\
\hline Abd. Circumference & -0.112 & 0.581 \\
\hline Systolic BP & -0.056 & 0.670 \\
\hline Diastolic BP & -0.173 & 0.425 \\
\hline Gender & 8.904 & 0.097 \\
\hline Insulin & -0.848 & 0.017 \\
\hline HOMA & - & - \\
\hline $\mathrm{HbA} 1 \mathrm{c}$ & -1.214 & 0.830 \\
\hline Cholesterol T & 0.028 & 0.711 \\
\hline HDL-C & -0.158 & 0.368 \\
\hline LDL-C & 0.026 & 0.795 \\
\hline TAG & -0.003 & 0.941 \\
\hline ApoA1 & -0.114 & 0.278 \\
\hline ApoB & 0.036 & 0.799 \\
\hline CRP & 0.567 & 0.378 \\
\hline Dopamine & -0.010 & 0.702 \\
\hline Epinephrine & 0.207 & 0.117 \\
\hline Norepinephrine & -0.018 & 0.329 \\
\hline Fasting plasma glucose & - & - \\
\hline 2h Glycemia & 0.043 & 0.487 \\
\hline RR Baseline & - & - \\
\hline Tidal volume & - & - \\
\hline $\begin{array}{r}\text { Dejour Test (\% } \\
\text { decrease RR) }\end{array}$ & - & - \\
\hline Conc NO & 0.049 & 0.296 \\
\hline CIMT right & -28.966 & 0.104 \\
\hline CIMT left & -6.871 & 0.652 \\
\hline \multicolumn{3}{|c|}{ Multivariable Analysis - Linear Regression - Stepwise Method } \\
\hline Insulin & $-0.841(-1.648:-0.035)^{*}$ & 0.042 \\
\hline
\end{tabular}

Variables to be tested in the multivariable analysis are chosen using the variables with a value of $P<0.25$ in the univariable analysis.

*Figures in parentheses indicate $95 \% \mathrm{Cl}$ for $\mathrm{B}$.

Abd. Cir, abdominal circumference; ApoA1, apolipoprotein A1; ApoB, apolipoprotein $B$; BMI, body mass index; CIMT, carotid intima-media thickness; CRP, C-reactive protein; HbA1c, glycated hemoglobin; HDL, high-density lipoprotein; HOMA, homeostatic model assessment; LDL, low-density lipoprotein; MV, minute volume; NO, nitric oxide; RR, respiratory rate; TAG, triglyceride.

previously seen in chronic heart failure patients $(20,33)$ as well as in animal studies in mice $(34,35)$.

The increased CB chemosensitivity observed in prediabetes patients in the present manuscript confirms our pre-clinical work in where we described an increased $\mathrm{CB}$ activity in prediabetes and type 2 diabetes rodent models, measured as increased neurotransmitters released from CB type cells $(4,6)$ by increased carotid sinus nerve basal activity $(5,7,8)$ and by increased spontaneous minute ventilation (4) and also supports the clinical imaging study performed by Cramer et al. describing that the CBs of type 2 diabetes patients are 20-25\% larger than control volunteers, indicating enlarged over functioning organs in the diabetic population (12). Additionally, it supports our hypothesis that insulin is a trigger for $\mathrm{CB}$ activation $(3,4,5,6,36)$ and the recent results by Vidal et al. (37) in where they show that insulin promotes hepatic glycogenolysis by acting on the CB. In agreement also with our findings, that CB chemosensitivity correlates with fasting plasma insulin levels, is the work by Barbosa et al. (38) where they show in humans that elevated plasma insulin increases minute ventilation independently of changes in glucose. More recently, the same authors examined the contribution of the $\mathrm{CB}$ chemoreceptors to the insulin-mediated increases in muscle sympathetic nerve activity (MSNA) in healthy humans and found that the attenuation of CB activity by low-dose dopamine or by hyperoxia, did not altered insulin-mediated increase MSNA burst frequency, suggesting that CB withdrawal in young, healthy men and women did not attenuate the sympathoexcitatory response to hyperinsulinemia (39). If at a first sight these results seem conflicting with our hypothesis that increased $\mathrm{CB}$ chemosensitivity promotes glucose homeostasis disruption due to the overactivation of the sympathetic nerve system, they are not, as we previously concluded that reductions in $\mathrm{CB}$ chemoreceptor activity positively affects insulin signaling pathways in visceral adipose tissue and liver, but not in skeletal muscle (9). Indeed, the study of Limberg et al. (39) corroborate our own since we also did not observe changes in glucose uptake in muscle after CSN ablations (9).

We observed no correlation between CB activity and cIMT or fasting blood glucose. This contrasts to what was previously suggested in disease paradigms of sleep apnea $(40,41)$, where increased cIMT has been proposed to be the trigger to $\mathrm{CB}$ overactivation, through hypoperfusion of the organs; and also in type 2 diabetes, where increased fasting blood glucose levels have been proposed as a stimuli to the CBs (42). Thus, in our experimental setting, overactivation of the CBs observed in prediabetes patients was not attributable to ischemic hypoxia of the carotid chemoreceptors, nor to hyperglycemia since our population was normoglycemic. The significant correlation disclosed between $\mathrm{CB}$ chemosensitivity and fasting insulin levels strongly suggests that insulin and not hypoxia or hyperglycemia is the main trigger for $\mathrm{CB}$ overactivation in prediabetes, as we previously reported in animal models of metabolic diseases. This is also in agreement with our rodent work in where we showed that hyperglycemia did not modify CSN activity (5). 
Table 4 Multivariable analysis between the dependent variables HOMA and $\mathrm{HbA} 1 \mathrm{c}$ and the independent variables using the stepwise method.

\begin{tabular}{|c|c|c|c|c|}
\hline \multirow[b]{2}{*}{ Independent variable } & \multicolumn{2}{|l|}{ HOMA } & \multicolumn{2}{|l|}{ HbA1c } \\
\hline & Unstandardized coefficients B & $P$-value & Unstandardized coefficients B & $P$ value \\
\hline \multicolumn{5}{|c|}{ Univariable Analysis - Linear Regression - Enter Method } \\
\hline Age & -0.004 & 0.907 & 0.134 & 0.498 \\
\hline BMI & 0.218 & 0.009 & 0.363 & 0.057 \\
\hline Abd. Circumference & 0.090 & 0.004 & 0.318 & 0.100 \\
\hline Systolic BP & 0.030 & 0.112 & 0.401 & 0.038 \\
\hline Diastolic BP & -0.006 & 0.832 & 0.197 & 0.325 \\
\hline Gender & -1.290 & 0.130 & -0.205 & 0.294 \\
\hline Insulin & - & - & - & - \\
\hline HOMA & - & - & 0.679 & $<0.001$ \\
\hline $\mathrm{HbA1c}$ & - & - & - & - \\
\hline Cholesterol T & -0.004 & 0.695 & 0.083 & 0.676 \\
\hline HDL-C & -0.042 & 0.112 & -0.290 & 0.134 \\
\hline LDL-C & -0.002 & 0.877 & 0.109 & 0.581 \\
\hline TAG & 0.006 & 0.173 & 0.367 & 0.055 \\
\hline ApoA1 & -0.017 & 0.326 & -0.289 & 0.152 \\
\hline ApoB & 0.016 & 0.400 & 0.345 & 0.084 \\
\hline CRP & 0.061 & 0.477 & 0.116 & 0.557 \\
\hline Dopamine & -0.004 & 0.436 & -0.107 & 0.694 \\
\hline Epinephrine & -0.028 & 0.206 & -0.105 & 0.670 \\
\hline Norepinephrine & 0.002 & 0.387 & 0.380 & 0.109 \\
\hline Fasting plasma Glucose & 0.025 & 0.230 & - & - \\
\hline 2h Glycemia & 0.007 & 0.441 & - & - \\
\hline RR Baseline & - & - & 0.302 & 0.183 \\
\hline Tidal volume & 0.155 & 0.447 & 0.224 & 0.329 \\
\hline DejoursTest (\% decrease RR) & -0.068 & 0.051 & -0.051 & 0.830 \\
\hline Conc NO & 0.002 & 0.730 & 0.210 & 0.336 \\
\hline CIMT right & 1.580 & 0.474 & 0.491 & 0.077 \\
\hline CIMT left & 1.824 & 0.436 & 0.373 & 0.050 \\
\hline \multicolumn{5}{|c|}{ Multivariable Analysis - Linear Regression - Stepwise Method ${ }^{\dagger}$} \\
\hline Abdominal Per. & $0.121(0.042,0.199)^{*}$ & 0.006 & - & - \\
\hline CB Chemosensitivity (\%) & $-0.082(-0.153,-0.012)^{*}$ & 0.026 & - & - \\
\hline HOMA & - & - & $0.098(0.020,0.175)^{\star}$ & 0.018 \\
\hline CIMT left & - & - & $1.176(0.044,2.308)^{*}$ & 0.043 \\
\hline
\end{tabular}

Variables to be tested in the multivariable analysis are chosen using the variables with a value of $P<0.25$ in the univariable analysis.

*Figures in parentheses indicate $95 \% \mathrm{Cl}$ for $\mathrm{B}$; ${ }^{\dagger} \mathrm{All}$ variables that were not statistically significant in each multivariable model were excluded. Abd. Circumference, abdominal circumference; ApoA1, apolipoprotein A1; ApoB, apolipoprotein B; BMI, body mass index; CIMT, carotid intima-media thickness; CRP, C-reactive protein; HbA1c, glycated hemoglobin; HDL, high-density lipoprotein; HOMA, homeostatic model assessment; LDL, low-density lipoprotein; MV, minute volume; NO, nitric oxide; RR, respiratory rate; TAG, triglyceride.

We observed no significant differences amongst nonprediabetes individuals and prediabetic patients in the risk factors assessed, except for hypertension which was not present in the control group volunteers; nor drug therapy, except for beta-blockers, which were more prevalent in the prediabetic group than in control group. CB overactivation has also been recently associated with the development of essential and resistant hypertension $(13,43)$. Thus, we tested the hypothesis that different responses to hyperoxia observed were not due to significantly different blood pressure. Surprisingly, although a significant difference in systolic blood pressure among groups was observed, no correlation was found between CB activity and this variable: the multivariable analysis between the dependent variable CB chemosensitivity (\% decrease in $\mathrm{RR}$ ) and the independent variable systolic blood pressure did not show a significant correlation among the variables $(P=0.670)$ indicating that, despite the differences found between the study population and control group, blood pressure is not related to $\mathrm{CB}$ overactivation.

This is not in agreement with the previous findings by Narkiewicz et al., describing that pathological afferent signaling emanating from $\mathrm{CB}$ drives sympathetically mediated elevations in blood pressure in resistant hypertension patients, a different study population that may justify the disparities with our study (44). Also, deactivation of $\mathrm{CB}$ chemoreceptors by hyperoxia decreased blood pressure in hypertensive patients (33) 
and CB unilateral ablation was associated to no change in blood pressure. However, eight patients showed significant reductions in ambulatory blood pressure overlapping with decreases in sympathetic activity (44); nevertheless, conclusions are difficult to drawn since metabolic parameters were not assessed in this pool of patients. Based on our findings, we believe that CB activity does not correlate directly with blood pressure in metabolic diseases patients, which suggests that aberrant discharges by the CBs lead to different disease phenotypes, according to the type of fibers activated in the carotid sinus nerve or the type of stimuli perpetrated. Further studies are required to disclose the selective modulation of specific nerve fibers in the CBs by distinct triggers.

In conclusion, we found that $\mathrm{CB}$ augmented chemosensitivity is a clinical feature of prediabetes that correlates with circulating plasma fasting insulin levels and with insulin sensitivity a core feature of dysmetabolism. This discovery conveys groundbreaking potential for early screening and diagnosis of metabolic diseases, based on non-invasive evaluation of CB activity, allowing identification of individuals that, lacking clinical signs of metabolic disease, are silently developing dysmetabolism promoted by $\mathrm{CB}$ overactivation and are putative candidates to therapeutic CB-specific modulation.

\section{Supplementary materials}

This is linked to the online version of the paper at https://doi.org/10.1530/ EJE-19-0976.

\section{Declaration of interest}

The authors declare that there is no conflict of interest that could be perceived as prejudicing the impartiality of this study.

\section{Funding}

This study was supported by Portuguese Foundation for Science and Technology Grants PTDC/SAU-ORG/111417/2009 and PD/BD/105890/2014.

\section{Author contribution statement}

Prof. Silvia Conde and Miguel Mota Carmo are the guarantors of the study. They had full access to all of the data in the study and take responsibility for the integrity of the data and the accuracy of the data analysis. Author contributions are as follows: Study concept and design: Conde, MotaCarmo, Guarino; Acquisition of data: Timóteo, Mota-Carmo, Selas, Conde, Caires, Sacramento, Ribeiro, Santiago; Analysis and interpretation of data: Conde, Guarino, Cunha-Guimarães, Mota-Carmo; Statistical analysis: Conde, Cunha-Guimarães, Timóteo; Drafting of the manuscript: Conde, Guarino; Critical revision of the manuscript for important intellectual content: all authors have reviewed and contributed to the intellectual content of the manuscript; Obtained funding: Conde; Administrative, technical, or material support: Conde, Selas, Caires; Study supervision: Conde, Mota-Carmo. Miguel Mota-Carmo and Silvia V Conde: both authors have contributed equally as senior authors to this manuscript.

\section{References}

1 Gonzalez C, Almaraz L, Obeso A \& Rigual R. Carotid body chemoreceptors: from natural stimuli to sensory discharges. Physiological Reviews 199474 829-898. (https://doi.org/10.1152/ physrev.1994.74.4.829)

2 Joyner MJ, Limberg JK, Wehrwein EA \& Johnson BD. Role of the carotid body chemoreceptors in glucose homeostasis and thermoregulation in humans. Journal of Physiology 2018596 3079-3085. (https://doi.org/10.1113/JP274354)

3 Conde SV, Ribeiro MJ, Melo BF, Guarino MP \& Sacramento JF. Insulin resistance: a new consequence of altered carotid body chemoreflex? Journal of Physiology 2017595 31-41. (https://doi.org/10.1113/ JP271684)

4 Ribeiro MJ, Sacramento JF, Gonzalez C, Guarino MP, Monteiro EC \& Conde SV. Carotid body denervation prevents the development of insulin resistance and hypertension induced by hypercaloric diets. Diabetes 201362 2905-2916. (https://doi.org/10.2337/db12-1463)

5 Conde SV, Sacramento JF \& Guarino MP. Carotid body: a metabolic sensor implicated in insulin resistance. Physiological Genomics 2018 50 208-214. (https://doi.org/10.1152/physiolgenomics.00121.2017) 6 Ribeiro MJ, Sacramento JF, Gallego-Martin T, Olea E, Melo BF, Guarino MP, Yubero S, Obeso A \& Conde SV. High fat diet blunts the effects of leptin on ventilation and on carotid body activity. Journal of Physiology 2018596 3187-3199. (https://doi.org/10.1113/JP275362)

7 Cracchiolo M, Sacramento JF, Mazzoni A, Panarese A, Carpaneto J, Conde SV \& Micera S. High frequency shift in carotid sinus nerve and sympathetic nerve activity in type 2 diabetic rat model. In 9th International IEEE/EMBS Conference on Neural Engineering (NER), pp. 498-501, 2019. (https://doi.org/10.1109/NER.2019.8717052)

8 Cracchiolo M, Sacramento JF, Mazzoni A, Panarese A, Carpaneto J, Conde SV \& Micera S. Decoding neural metabolic markers from the carotid sinus nerve in a Type 2 diabetes model. IEEE Transactions on Neural Systems and Rehabilitation Engineering 201927 2034-2043. (https://doi.org/10.1109/TNSRE.2019.2942398)

9 Sacramento JF, Ribeiro MJ, Rodrigues T, Olea E, Melo BF, Guarino MP, Fonseca-Pinto R, Ferreira CR, Coelho J, Obeso A et al. Functional abolition of carotid body activity restores insulin action and glucose homeostasis in rats: key roles for visceral adipose tissue and the liver. Diabetologia 201760 158-168. (https://doi.org/10.1007/s00125-0164133-y)

10 Dos Santos E, Sacramento JF, Melo BF \& Conde SV. Carotid body dysfunction in diet-induced insulin resistance is associated with alterations in its morphology. Advances in Experimental Medicine and Biology 2018 1071 103-108. (https://doi.org/10.1007/978-3-31991137-3_13)

11 Cramer JA, Wiggins RH, Fudim M, Engelman ZJ, Sobotka PA \& Shah LM. Carotid body size on CTA: correlation with comorbidities. Clinical Radiology 201469 e33-e36. (https://doi.org/10.1016/j. crad.2013.08.016)

12 Sacramento JF, Chew DJ, Melo BF, Donegá M, Dopson W, Guarino MP, Robinson A, Prieto-Lloret J, Patel S, Holinski BJ et al. Bioelectronic modulation of carotid sinus nerve activity in the rat: a potential therapeutic approach for type 2 diabetes. Diabetologia 2018 61 700-710. (https://doi.org/10.1007/s00125-017-4533-7)

13 Abdala AP, McBryde FD, Marina N, Hendy EB, Engelman ZJ, Fudim M, Sobotka PA, Gourine AV \& Paton JF. Hypertension is critically dependent on the carotid body input in the spontaneously hypertensive rat. Journal of Physiology 2012590 4269-4277. (https:// doi.org/10.1113/jphysiol.2012.237800)

14 McBryde FD, Abdala AP, Hendy EB, Pijacka W, Marvar P, Moraes DJ, Sobotka PA \& Paton JF. The carotid body as a putative therapeutic target for the treatment of neurogenic hypertension. Nature Communications 20134 2395. (https://doi.org/10.1038/ ncomms3395)

15 Fletcher EC, Lesske J, Behm R, Miller CC, Stauss H \& Unger T. Carotid chemoreceptors, systemic blood pressure, and chronic episodic 
hypoxia mimicking sleep apnea. Journal of Applied Physiology 199272 1978-1984. (https://doi.org/10.1152/jappl.1992.72.5.1978)

16 Peng YJ, Overholt JL, Kline D, Kumar GK \& Prabhakar NR. Induction of sensory long-term facilitation in the carotid body by intermittent hypoxia: implications for recurrent apneas. PNAS 2003100 10073-10078. (https://doi.org/10.1073/pnas.1734109100)

17 Gonzalez-Martín MC, Vega-Agapito MV, Conde SV, Castañeda J, Bustamante R, Olea E, Perez-Vizcaino F, Gonzalez C \& Obeso A. Carotid body function and ventilatory responses in intermittent hypoxia. Evidence for anomalous brainstem integration of arterial chemoreceptor input. Journal of Cellular Physiology 2011226 1961-1969. (https://doi.org/10.1002/jcp.22528)

18 Del Rio R, Marcus NJ \& Schultz HD. Carotid chemoreceptor ablation improves survival in heart failure: rescuing autonomic control of cardiorespiratory function. Journal of the American College of Cardiology 201362 2422-2430. (https://doi.org/10.1016/j.jacc.2013.07.079)

19 Despas F, Detis N, Dumonteil N, Labrunee M, Bellon B, Franchitto N, Galinier M, Senard JM \& Pathak A. Excessive sympathetic activation in heart failure with chronic renal failure: role of chemoreflex activation. Journal of Hypertension 200927 1849-1854. (https://doi. org/10.1097/HJH.0b013e32832e8d0f)

20 Despas F, Lambert E, Vaccaro A, Labrunee M, Franchitto N, Lebrin M, Galinier M, Senard JM, Lambert G, Esler M et al. Peripheral chemoreflex activation contributes to sympathetic baroreflex impairment in chronic heart failure. Journal of Hypertension 201230 753-760. (https://doi.org/10.1097/HJH.0b013e328350136c)

21 Franchitto N, Despas F, Labrunee M, Roncalli J, Boveda S, Galinier M, Senard JM \& Pathak A. Tonic chemoreflex activation contributes to increased sympathetic nerve activity in heart failure-related anemia. Hypertension 201055 1012-1017. (https://doi.org/10.1161/ HYPERTENSIONAHA.109.146779)

22 Somers VK, Dyken ME, Clary MP \& Abboud FM. Sympathetic neural mechanisms in obstructive sleep apnea. Journal of Clinical Investigation 199596 1897-1904. (https://doi.org/10.1172/JCI118235)

23 Narkiewicz K, van de Borne PJ, Pesek CA, Dyken ME, Montano N $\&$ Somers VK. Selective potentiation of peripheral chemoreflex sensitivity in obstructive sleep apnea. Circulation 199999 1183-1189. (https://doi.org/10.1161/01.cir.99.9.1183)

24 Vera-Cruz P, Guerreiro F, Ribeiro MJ, Guarino MP \& Conde SV. Hyperbaric oxygen therapy improves glucose homeostasis in Type 2 diabetes patients: a likely involvement of the carotid bodies. Advances in Experimental Medicine and Biology 2015860 221-225. (https://doi.org/10.1007/978-3-319-18440-1_24)

25 Kumar P \& Prabhakar NR. Peripheral chemoreceptors: function and plasticity of the carotid body. Comprehensive Physiology 20122 141-219. (https://doi.org/10.1002/cphy.c100069)

26 Thorp AA \& Schlaich MP. Relevance of sympathetic nervous system activation in obesity and metabolic syndrome. Journal of Diabetes Research 20152015 341583. (https://doi.org/10.1155/2015/341583)

27 American Diabetes Association. Diagnosis and classification of diabetes mellitus. Diabetes Care 201336 (Supplement 1) S67-S74. (https://doi.org/10.2337/dc13-S067)

28 Touboul PJ, Hennerici MG, Meairs S, Adams H, Amarenco P, Desvarieux M, Ebrahim S, Fatar M, Hernandez Hernandez R et al. Advisory Board of the 3rd Watching the Risk Symposium 2004, 13th European Stroke Conference. Mannheim carotid intima media thickness Consensus. Cerebrovascular Disease 200418 346-349. (https://doi.org/10.1159/000081812)

29 Dejours P. Control of respiration by arterial chemoreceptors. Annals of the New York Academy of Sciences 1963109 682-695. (https://doi. org/10.1111/j.1749-6632.1963.tb13497.x)

30 Dejours P. Chemoreflexes in breathing. Physiological Reviews 196242 335-358. (https://doi.org/10.1152/physrev.1962.42.3.335)
31 Chardon K, Telliez F, Bach V, Leke A, Delanaud S, Bouferrache B, Libert JP \& Gaultier C. Effects of warm and cool thermal conditions on ventilatory responses to hyperoxic test in neonates. Respiratory Physiology and Neurobiology 2004140 145-153. (https://doi. org/10.1016/j.resp.2003.11.007)

32 Gautier H. Honoring Pierre Dejours: his contribution to the study of the role of the arterial chemoreceptors in the regulation of breathing in humans. Advances in Experimental Medicine and Biology 2003536 1-7. (https://doi.org/10.1007/978-1-4419-9280-2_1)

33 Sinski M, Lewandowski J, Przybylski J, Zalewski P, Symonides B, Abramczyk P \& Gaciong Z. Deactivation of carotid body chemoreceptors by hyperoxia decreases blood pressure in hypertensive patients. Hypertension Research 201437 858-862. (https://doi.org/10.1038/hr.2014.91)

34 Kline DD, Peng YJ, Manalo DJ, Semenza GL \& Prabhakar NR. Defective carotid body function and impaired ventilatory responses to chronic hypoxia in mice partially deficient for hypoxia-inducible factor 1 alpha. PNAS 200299 821-826. (https://doi.org/10.1073/ pnas.022634199)

35 Soliz J, Soulage C, Borter E, van Patot MT \& Gassmann M. Ventilatory responses to acute and chronic hypoxia are altered in female but not male Paskin-deficient mice. American Journal of Physiology: Regulatory, Integrative and Comparative Physiology 2008295 R649-R658. (https://doi.org/10.1152/ajpregu.00876.2007)

36 Conde SV, Sacramento JF, Guarino MP, Gonzalez C, Obeso A, Diogo LN, Monteiro EC \& Ribeiro MJ. Carotid body, insulin, and metabolic diseases: unraveling the links. Frontiers in Physiology 20145 418. (https://doi.org/10.3389/fphys.2014.00418)

37 Vidal ML, Villegas SAM, Rubio CZV, Cruz SAM \& Dorronsoro ER. Insulin in the carotid sinus increases suprahepatic and arterial glucose levels. Revista Cubana de Investigaciones Biomedicas 201938 e102.

38 Barbosa TC, Kaur J, Holwerda SW, Young CN, Curry TB, Thyfault JP, Joyner MJ, Limberg JK \& Fadel PJ. Insulin increases ventilation during euglycemia in humans. American Journal of Physiology: Regulatory, Integrative and Comparative Physiology 2018315 R84-R89. (https://doi.org/10.1152/ajpregu.00039.2018)

39 Limberg JK, Johnson BD, Mozer MT, Holbein WW, Curry TB, Prabhakar NR \& Joyner MJ. Role of the carotid chemoreceptors in insulin-mediated sympathoexcitation in humans. American Journal of Physiology: Regulatory, Integrative and Comparative Physiology 2020 318 R173-R181. (https://doi.org/10.1152/ajpregu.00257.2019)

40 Kasai T, Floras JS \& Bradley TD. Sleep apnea and cardiovascular disease: a bidirectional relationship. Circulation 2012126 1495-1510. (https://doi.org/10.1161/CIRCULATIONAHA.111.070813)

41 Prabhakar NR, Peng YJ, Jacono FJ, Kumar GK \& Dick TE. Cardiovascular alterations by chronic intermittent hypoxia: importance of carotid body chemoreflexes. Clinical and Experimental Pharmacology and Physiology 200532 447-449. (https://doi. org/10.1111/j.1440-1681.2005.04209.x)

42 Koyama Y, Coker RH, Stone EE, Lacy DB, Jabbour K, Williams PE \& Wasserman DH. Evidence that carotid bodies play an important role in glucoregulation in vivo. Diabetes 200049 1434-1442. (https://doi. org/10.2337/diabetes.49.9.1434)

43 Paton JF, Ratcliffe L, Hering D, Wolf J, Sobotka PA \& Narkiewicz K. Revelations about carotid body function through its pathological role in resistant hypertension. Current Hypertension Reports 201315 273-280. (https://doi.org/10.1007/s11906-013-0366-z)

44 Narkiewicz K, Ratcliffe LE, Hart EC, Briant LJ, Chrostowska M, Wolf J, Szyndler A, Hering D, Abdala AP, Manghat N et al. Unilateral carotid body resection in resistant hypertension: a safety and feasibility trial. JACC: Basic to Translational Science 20161 313-324. (https://doi. org/10.1016/j.jacbts.2016.06.004)

Received 1 December 2019

Revised version received 19 February 2020

Accepted 26 March 2020 